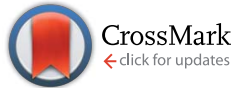

Cite this: RSC Adv., 2017, 7, 15952

Received 7th January 2017 Accepted 25th February 2017

DOI: $10.1039 / \mathrm{c} 7 \mathrm{ra00273d}$

rsc.li/rsc-advances

\section{Experimental and theoretical studies on solvation in aqueous solutions of ionic liquids carrying different side chains: the $n$-butyl-group versus the methoxyethyl group $\uparrow$}

\author{
Jéssica C. de Jesus, ${ }^{a}$ Paulo A. R. Pires, ${ }^{a}$ Rizwana Mustafa, ${ }^{\text {b Naheed Riaz }}{ }^{\text {b }}$ \\ and Omar A. El Seoud*a
}

\begin{abstract}
We used solvatochromic compounds to probe solvation in mixtures of water, W, and four ionic liquids (ILs), 1-R-3-methylimidazolium $\mathrm{X}$, where $\mathrm{R}=n$-butyl or methoxyethyl and $\mathrm{X}=$ acetate and chloride; these are denoted as $\left(\mathrm{C}_{4}\right.$ MelmAc), $\left(\mathrm{C}_{3} \mathrm{OMelmAc}\right),\left(\mathrm{C}_{4} \mathrm{MelmCl}\right)$, and $\left(\mathrm{C}_{3} \mathrm{OMelmCl}\right)$. Our aim was to investigate the effects on solvation when an ether linkage is substituted for a $-\mathrm{CH}_{2}-$ group in the IL side chain. We used the solvatochromic probes 2,6-dichloro-4-(2,4,6-triphenylpyridinium-1-yl)phenolate (WB) and 5nitroindoline, 1-methyl-5-nitroindoline to determine the solvent polarity, $E_{\mathrm{T}}(\mathrm{WB})$, and Lewis basicity, SB, respectively. From UV-Vis spectral data, we calculated $E_{T}(\mathrm{WB})$ as a function of the water mole fraction $\left(\chi_{W}\right)$ at different temperatures; from 15 to $60{ }^{\circ} \mathrm{C}$ for WB in IL-acetate-W; $25^{\circ} \mathrm{C}$ for SB and WB in ILchloride-W. For all IL-W mixtures, the dependence of $E_{T}(\mathrm{WB})$ on $\chi_{\mathrm{W}}$ is non-linear and, surprisingly, shows negligible dependence on the nature of the side chain. Values of the SB of IL-W were higher for $\mathrm{C}_{4}$ MelmX-W than for $\mathrm{C}_{3} \mathrm{OMelmX}$. A rationale for these results is the deactivation of the ether oxygen due to the formation of intramolecular hydrogen bonds with the hydrogens of the imidazolium ring. Our hypothesis is confirmed by quantum chemistry and molecular dynamics calculations (energy of the conformers and radial distribution functions), density, and ${ }^{1} \mathrm{H}$ NMR data (chemical shifts, line widths). We attributed the non-linear dependence of the solvatochromic parameters on $\chi_{\mathrm{W}}$ to preferential solvation of the dyes. We treated $E_{\mathrm{T}}(\mathrm{WB})$ data with a model that includes the formation of the complex solvent IL$W$. Equilibrium constants for solvent exchange in the solvation layer of WB were calculated; their values showed that IL-W is the most efficient solvent species present.
\end{abstract}

\section{Introduction}

Ionic liquids (ILs) are composed only of ions and have, by operational definition, melting points $<100{ }^{\circ} \mathrm{C}$. The most extensively studied ILs are derivatives of imidazole that are substituted at both nitrogen atoms. Their structural versatility can be demonstrated by the fact that it is possible to synthesize 144 ILs based on 1,3-dialkylimidazolium bromides, chlorides, and iodides, with $\mathrm{C}_{1}$ to $\mathrm{C}_{4}$ as $n$-alkyl groups. This structural versatility results in different physicochemical properties including, inter alia, viscosity, polarity, and miscibility with water and other molecular solvents. ${ }^{\mathbf{1 - 4}}$

ILs with an ether linkage in the side chain have attracted considerable attention. This is because the introduction of this

${ }^{a}$ Institute of Chemistry, The University of São Paulo, 748 Professor Lineu Prestes Av., 05508-000 São Paulo, SP, Brazil.E-mail: elseoud@usp.br

${ }^{b}$ Department of Chemistry, The University of Bahawalpur, Bahawalpur 63100, Pakistan

$\dagger$ Electronic supplementary information (ESI) available. See DOI: 10.1039/c7ra00273d functional group leads to clear modifications of the physicochemical properties of the IL relative to that with an alkyl group, e.g., four carbon atoms of the $n$-butyl group versus three carbons plus oxygen of the 2-methoxyethyl group. For example, introduction of the ether functional group in the IL leads to a reduction in viscosity relative to the corresponding IL with an alkyl side chain with the same anion. ${ }^{5-10}$ Due to their low viscosities, high conductivities, and electrochemical stability, ILs with ether functional groups are used as electrolytes in lithium batteries, electric double layer capacitors, dyesensitized photoelectrochemical solar cells, ${ }^{\mathbf{1 1 - 1 4}}$ absorption of acidic combustion gases, ${ }^{\mathbf{1 5}, \mathbf{1 6}}$ and the dissolution of a variety of carbohydrates. ${ }^{\mathbf{1 7 , 1 8}}$ In the latter application, it was shown that polar ILs with a large difference between their solvent Lewis basicity, SB, and Lewis acidity, SA, can dissolve cellulose. ${ }^{19}$ Note that functionalized ILs are task-specific; i.e., they may perform an additional role besides acting as solvents. ${ }^{\mathbf{2 0 - 2 2}}$

Mixtures of ionic liquids, water (W), and other molecular solvents are used for practical reasons. These include "tuning" of the properties of a binary mixture by changing its 

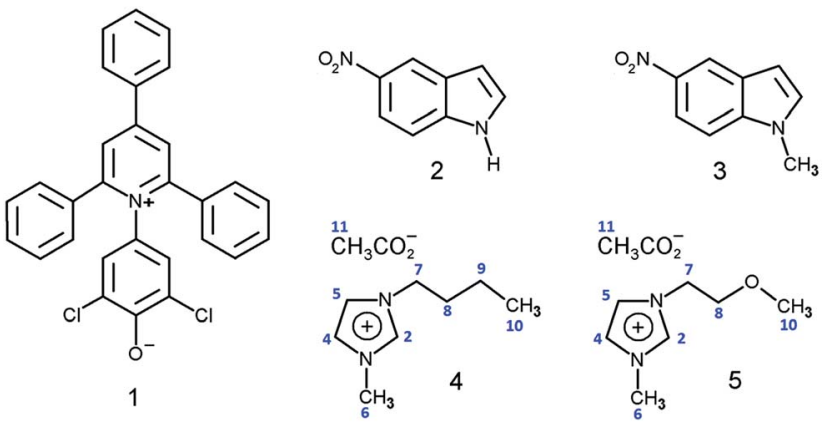

Fig. 1 Molecular structures of substances of interest in this work. These are: 2,6-dichloro-4-(2,4,6-triphenylpyridinium-1-yl)phenolate, WB, 1; 5-nitroindoline, NI, 2; 1-methyl-5-nitroindoline, MeNI, 3; 1-(nbutyl)-3-methylimidazolium, $\mathrm{C}_{4}$ MelmAc, 4; and 1-(methoxyethyl)-3methylimidazolium acetate, $\mathrm{C}_{3} \mathrm{OMelmAc}, 5$. IL-chlorides are not depicted.

composition, increasing the reactant diffusion coefficients due to the concomitant decrease in viscosity (as indicated by the Stokes-Einstein diffusion equation), and cost reduction. The effect of decreasing viscosity on reactivity was nicely demonstrated by the observed increase in the rates of Diels-Alder reactions as a result of decreasing the viscosity of the medium, both for pure ILs and their aqueous solutions. ${ }^{23,24}$ The use of aqueous ILs for pulp fractionation, fiber spinning, ${ }^{25}$ and as additives for improving dying of natural and synthetic fibers ${ }^{26}$ are interesting examples of the potential applications of green chemistry to improve these important industrial processes.

The rational use of mixtures of ILs with $\mathrm{W}$ and other molecular solvents, however, is deceptively simple. The reason is that the dependence of mixture properties on composition is usually non-ideal. ${ }^{4}$ This non-ideality covers both macroscopic properties, e.g. , viscosity, surface tension, and conductivity, ${ }^{27-29}$ and microscopic ones, e.g., solvent empirical polarity, SA, and $\mathrm{SB}^{30,31}$ The latter properties are determined by the use of solvatochromic dyes (hereafter designated as "probes"). ${ }^{32-34}$ These are compounds whose UV-Vis spectra, absorption or emission, are particularly sensitive to a specific solvent property. An example is solvent empirical polarity, $E_{\mathrm{T}}$ (probe), which is calculated from the dependence of $\lambda_{\max }$ of the intramolecular charge transfer band on the nature of the solvent or the composition of the solvent mixture. ${ }^{3,22,35}$

$$
E_{\mathrm{T}}(\text { probe }) /\left(\mathrm{kcal} \mathrm{mol}^{-1}\right)=28590.5 / \lambda_{\max }(\mathrm{nm})
$$

In the present work, we used the following solvatochromic probes to study solvation in several IL-W binary mixtures (probe name and acronym, binary mixture property): 2,6-dichloro-4(2,4,6-triphenylpyridinium-1-yl)phenolate (WB), empirical solvent polarity $E_{\mathrm{T}}(\mathrm{WB})$; 5-nitroindoline (NI) and 1-methyl-5nitroindoline (MeNI), SB. The ionic liquids were of the form 1-R-3-methylimidazoliumX, where $\mathrm{R}=n$-butyl and methoxyethyl and $\mathrm{X}=$ acetate or chloride, and are denoted as $\left(\mathrm{C}_{4^{-}}\right.$ MeImAc), ( $\left.\mathrm{C}_{3} \mathrm{OMeImAc}\right),\left(\mathrm{C}_{4} \mathrm{MeImCl}\right)$, and $\left(\mathrm{C}_{3} \mathrm{OMeImCl}\right)$; see Fig. 1. We examined $E_{\mathrm{T}}(\mathrm{WB})$ as a function of $\chi_{\mathrm{W}}$ over the entire composition range ( $\chi_{\mathrm{W}}$ from 0.1 to 0.95$)$ at four different temperatures, $15,25,40$, and $60^{\circ} \mathrm{C}$ (IL-acetates). Measurements of the $E_{\mathrm{T}}(\mathrm{WB})$ of IL-chlorides and the SB of all IL-W mixtures were carried out at $25^{\circ} \mathrm{C}$.

All plots of $E_{\mathrm{T}}(\mathrm{WB})$ and $\mathrm{SB}$ versus $\chi_{\mathrm{W}}$ were non-linear at all temperatures. Surprisingly, pure $\mathrm{C}_{3} \mathrm{OMeImAc}$ is only slightly more polar than pure $\mathrm{C}_{4} \mathrm{MeImAc}$, although $\mathrm{C}_{3} \mathrm{OMeImAc}-\mathrm{W}$ is slightly less polar than $\mathrm{C}_{4} \mathrm{MeImAc}-\mathrm{W}$ in the $\chi_{\mathrm{W}}$ range $0.1-0.67$, becoming more polar at higher $\chi_{\mathrm{W}}$. Similarly, at $25{ }^{\circ} \mathrm{C}, \mathrm{C}_{3^{-}}$ OMeImCl-W is more polar than $\mathrm{C}_{4} \mathrm{MeImCl}-\mathrm{W}$ in the $\chi_{\mathrm{W}}$ range 0.4-0.95. Mixtures of $\mathrm{C}_{4} \mathrm{MeImX}-\mathrm{W}$ are more basic than the corresponding $\mathrm{C}_{3} \mathrm{OMeImX}-\mathrm{W}$, where $\mathrm{X}=$ acetate and chloride, within the $\chi_{\mathrm{w}}$ ranges studied.

These results are analyzed in terms of "deactivation" of the ether functionality of $\mathrm{C}_{3} \mathrm{OMeImX}$ due to its hydrogen bonding with the relatively acidic hydrogens of the imidazolium ring, in particular $\mathbf{C 2 - H}$. This interpretation is corroborated by theoretical calculations (quantum chemistry and molecular dynamics simulations, MD), density, and ${ }^{1} \mathrm{H}$ NMR spectral data (chemical shifts and line widths).

We analyzed the $E_{\mathrm{T}}(\mathrm{WB})$ data using a solvation model where the medium consists of the two pure solvents plus a "complex" one, IL-W, formed by interactions (dipolar and hydrogen bonding) between its two components. We calculated the concentrations of these complex solvents from accurate density data; see Fig. ESI- $1 \dagger$ (Fig. 1 of the ESI $\dagger$ ). The effective concentrations of all binary mixture components were then employed to calculate the local compositions in the solvation layer of WB. Our calculations indicated that IL-W are the most efficient solvent species; i.e., they displace IL and $\mathrm{W}$ from the solvation layer of WB. Recently, a paper was published on the solvatochromism of Reichardt betaine (RB; 2,6-diphenyl-4-(2,4,6triphenylpyridinium-1-yl)phenolate) in the same solvent mixture at $25{ }^{\circ} \mathrm{C}$. In addition to studying at a single temperature, the emphasis in this publication was to fit the RedlichKister equation to the data without extracting information about the local composition of the solvation layer of RB. ${ }^{36}$

\section{Experimental}

\subsection{Material}

We purchased the solvents and reactants from Merck or Synth (São Paulo) and purified them as recommended elsewhere. ${ }^{37}$ The probes WB, NI, and MeNI were available from previous studies; $;^{\mathbf{4} 38}$ deionized water was used throughout.

\subsection{Synthesis of RMeImX ( $R=n$-butyl and methoxyethyl; $X$ $=$ acetate and chloride)}

We synthesized these ILs according to Scheme 1:

We transformed the $\mathrm{IL}-\mathrm{Cl}$ into $\mathrm{IL}-\mathrm{OH}$ by $\mathrm{Cl}^{-} / \mathrm{OH}^{-}$anion exchange and neutralized the latter IL with acetic acid. Briefly, $\mathrm{C}_{4} \mathrm{MeImCl}$, was prepared by reacting $19.5 \mathrm{~mL}$ of 1-methylimidazole $(0.25 \mathrm{~mol})$ with $24.0 \mathrm{~mL}$ of 1 -chlorobutane $(0.23 \mathrm{~mol})$ in $75 \mathrm{~mL}$ of acetonitrile in a PTFE-coated stainless-steel reactor (10 bar, $\mathrm{N}_{2}$ atmosphere, $110{ }^{\circ} \mathrm{C}, 6 \mathrm{~h}$ ). After cooling the product and removing acetonitrile, the resultant $\mathrm{C}_{4} \mathrm{MeImCl}$ was washed with cold ethyl acetate (thrice; each $75 \mathrm{~mL}$; vigorous agitation) 
1)<smiles>[R]OCl</smiles>

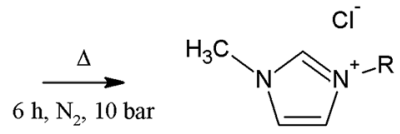

2)

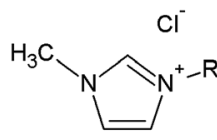

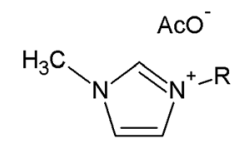

Scheme 1 Synthesis of the ILs; $R$ represents 1-chlorobutane $\left(\mathrm{C}_{4}\right.$ MelmX) or 1-chloro-2-methoxyethane $\left(\mathrm{C}_{3} \mathrm{OMelmX}\right) ; \mathrm{X}=$ acetate and chloride.

and dried at $40{ }^{\circ} \mathrm{C}$ under reduced pressure over $\mathrm{P}_{4} \mathrm{O}_{10}$ for $72 \mathrm{~h}$. The product ( $94.4 \%$ yield) is a white solid, $\mathrm{mp} 40-41^{\circ} \mathrm{C}$, which gave the expected ${ }^{1} \mathrm{H}$ NMR spectrum (Bruker DRX-500 spectrometer, $500 \mathrm{MHz}$ for ${ }^{1} \mathrm{H}$, solution in $\mathrm{CDCl}_{3}$, see Table ESI-1, Table 1 of ESI $\dagger)^{39}$

We converted $\mathrm{C}_{4} \mathrm{MeImCl}$ into $\mathrm{C}_{4} \mathrm{MeImOH}$ by ion exchange on a macroporous resin (Purolite SGA-550-OH; hydroxide form). In a typical experiment, we dissolved $15 \mathrm{~g}$ of $\mathrm{C}_{4} \mathrm{MeImCl}(0.1 \mathrm{~mol})$ in $500 \mathrm{~mL}$ of methanol and slowly passed the solution through a column containing $180 \mathrm{~mL}$ of the above-mentioned resin ( $0.144 \mathrm{~mol} \mathrm{OH}^{-}$; equilibrated with methanol). We tested the completeness of $\mathrm{Cl}^{-} / \mathrm{OH}^{-}$exchange using $\mathrm{AgNO}_{3} / \mathrm{HNO}_{3}$ solution. The produced $\mathrm{C}_{4} \mathrm{MeImOH}$ was promptly neutralized with a cold solution of acetic acid in methanol (expanded-scale pH paper) before removing the alcohol under reduced pressure and drying, which yielded a clear, slightly yellowish liquid that gave the expected ${ }^{1} \mathrm{H}$ NMR spectrum; see Table ESI-1. $\dagger$

A similar procedure was employed for 1-(methoxyethyl)-3methylimidazolium chloride, $\mathrm{C}_{3} \mathrm{OMeImCl}$, by reacting 1-methylimidazole and 1-chloro-2-methoxyethane in acetonitrile under pressure, except that the reactant volumes were different. The product $\left(93.2 \%\right.$ yield) is a white solid, $\mathrm{mp} 71-72{ }^{\circ} \mathrm{C}$, that gave the expected ${ }^{1} \mathrm{H}$ NMR spectrum (Bruker DRX-500 spectrometer, solution in $\mathrm{CDCl}_{3}$, see Table ESI-1†). We converted $\mathrm{C}_{3} \mathrm{OMeImCl}$ into $\mathrm{C}_{3} \mathrm{OMeImAc}$ by the same procedure used for $\mathrm{C}_{4} \mathrm{MeImAc}$; the final yield was $88.5 \%$.

\subsection{Sample preparation for solvatochromic measurements}

Binary mixtures of IL-W ( 7 for IL-Cl and 16 for IL-Ac) were prepared by weight at $25{ }^{\circ} \mathrm{C}$ to cover a $\chi_{\mathrm{W}}$ range of 0.10 to 0.95 . WB solutions in acetone were pipetted into $1 \mathrm{~mL}$ volumetric tubes and dried under reduced pressure over $\mathrm{P}_{4} \mathrm{O}_{10}$. We added pure $\mathrm{IL}$, pure $\mathrm{W}$, and binary $\mathrm{IL}-\mathrm{W}$ mixtures to the solid $\mathrm{WB}$ samples; the probe was dissolved with the aid of a tube rotator (Labquake, Lab Industries; $30 \mathrm{~min}$ ). The same procedure was employed for the solvatochromic homomorphic pair NI and MeNI.

\subsection{Spectrophotometric determination of $E_{\mathrm{T}}(\mathrm{WB})$ and SB}

The final probe concentration was $2-5 \times 10^{-4} \mathrm{~mol} \mathrm{~L}^{-1}$ for all probes. UV-Vis spectra of the probe solutions showed no changes in $l_{\max }$ or the shape of the charge-transfer band as a function of probe concentration in the range $1 \times 10^{-4}$ to $5 \times$

$10^{-4} \mathrm{~mol} \mathrm{~L}^{-1}$. This shows that there is no detectable probe aggregation under our experimental conditions. We used a Shimadzu UV-2550 UV-Vis spectrophotometer provided with a digital thermometer (model 4000A, Yellow Springs Instrument) that measured the temperature $\left( \pm 0.05^{\circ} \mathrm{C}\right)$ inside the cellholder. We recorded each spectrum 3 times at a resolution of $0.2 \mathrm{~nm}$ and determined the values of $\lambda_{\max }$ from the first derivative of the absorption spectrum. The uncertainty in $E_{\mathrm{T}}(\mathrm{WB})$ is $\leq 0.04 \mathrm{kcal} \mathrm{mol}^{-1}$ (spectral range $\left.=400-500 \mathrm{~nm}\right)$.

\subsection{Density measurements}

We measured the densities of the above-mentioned liquids (pure solvents and binary mixtures), at $15,25,40$, and $60{ }^{\circ} \mathrm{C}$, using a DMA $4500 \mathrm{M}$ resonating-tube density meter (Anton Paar).

\section{$2.6 \quad{ }^{1} \mathrm{H}$ NMR study of IL solutions in $\mathrm{CDCl}_{3}$}

The ILs were weighed in $2 \mathrm{~mL}$ volumetric tubes, dried under reduced pressure for $6 \mathrm{~h}$ in the presence of $\mathrm{P}_{4} \mathrm{O}_{10}$, and weighed again; the volume was made up to $2 \mathrm{~mL}$ with dry $\mathrm{CDCl}_{3}$. The solutions were transferred to a Wilmad 535 NMR-tube and the spectra were recorded at $25{ }^{\circ} \mathrm{C}$ using a Bruker DRX-500 spectrometer (64 scans; $2 \mathrm{~s}$ acquisition time). We calculated chemical shifts $(\delta)$ and line widths at half heights $(\Delta \nu)$ from the spectra using the MestRe-C program package version 4.5.9.1 (Mestrelab Research, Santiago de Compostela).

\subsection{Theoretical calculations}

2.7.1 Quantum chemical calculations. We used Gaussian09, E. 01, to analyze the presence of intramolecular hydrogen bonding in $\mathrm{C}_{3} \mathrm{OMeIm}^{+}$. Two limiting conformations of this cation were employed as starting inputs: one with the side chain fully extended (designated as linear) and the other with the oxygen atom close to $\mathrm{C} 2-\boldsymbol{H}$ (designated as cyclic); see Fig. 6A and $\mathrm{C}$ for geometry optimized versions of these conformations. ${ }^{40}$

The geometries of these structures were optimized in the gas phase using the hybrid density functional B3LYP in conjunction with the 6-311++G(d,p) basis set. Subsequently, we scanned the dihedral angles formed by atoms $\mathrm{C} 2-\mathrm{N} 1-\mathrm{C} 7-\mathrm{C} 8$ of conformers A and C in Fig. 6, (see atom numbering in Fig. 1) from 0 to $360^{\circ}$ in $15^{\circ}$ steps, and calculated the corresponding electronic energy after each step. We repeated the same calculation steps for the IL-cation in water using the implicit solvation model (PCM) as implemented in the Gaussian program package. We present the results of all these calculations in Fig. 5 below.

2.7.2 Molecular dynamics, MD simulations. We used the Gromacs 5.1 software package. ${ }^{41}$ The force field used was GAFF. ${ }^{42}$ The compositions of the systems that we simulated are listed in Table ESI-2. $\dagger$

Simulation strategy. We optimized the (gas phase) geometry of WB and IL using density functional theory (DFT) calculations, employing the "good-opt" parameter implemented in the Orca 2.9 program. ${ }^{43}$ Partial charges on the atoms were calculated using the RESP (Restrained ElectroStatic Potential fit) approach $^{44,45}$ as calculated with the RED on-line server (RESP 
ESP charge Derive). ${ }^{46}$ The topology files for GAFF (General Amber Force Field) were generated using Acpype ${ }^{47}$ and Antechamber 12 programs. ${ }^{48}$ The GAFF-optimized geometry and topology of SPC/E water were obtained with the Gromacs package. The simulation boxes were generated by using the Packmol program. ${ }^{49}$

Considering that all binary solvent mixtures are viscous and have an ionic component, we proceeded as follows in order to guarantee the robustness of the calculation results: in the first or equilibration phase, we equilibrated each system using a canonical ensemble $(N V T)$ for 100 ps followed by an isothermal-isobaric ensemble $(N p T)$ for another $100 \mathrm{ps}$. We carried a subsequent production phase for $40 \mathrm{~ns}$ and then examined the system potential energy and density as a function of simulation time. Normally, both properties reached essentially constant values after $c a$. 10 ns from the start of the production phase. The system was then "annealed" as follows: the simulation boxes were heated from 298 to $370 \mathrm{~K}$ over $2 \mathrm{~ns}$ under constant volume, kept at $370 \mathrm{~K}$ for $6 \mathrm{~ns}$, cooled to $298 \mathrm{~K}$ over $2 \mathrm{~ns}$ with an additional pressure equilibration to 1 bar for $0.25 \mathrm{~ns}$ (under $N p T$ ensemble), and subjected to a production phase for $40 \mathrm{~ns}$. The results of this "annealing" were usually in excellent agreement with those of the first run. Therefore, each system reached equilibrium during the first run; we report here such results (first run).

We used the radial distribution function (RDF) of pairs of atoms and minimum distances of residues to calculate the extension of the solvation layer of WB in $\mathrm{nm}$ and the number of solvent species in this layer; vide infra.

Validation and analysis of simulation data. We used densities to validate the simulation results. After the first production phase, the calculated system densities were $\rho=1.06030$ (A1), 1.08662 (B1), 1.11129 (C1), 1.17290 (A2), 1.13555 (B2), and 1.18104 (C2) $\mathrm{g} \mathrm{mL}^{-1}$; see Table ESI- $\uparrow \uparrow$ for the compositions of mixtures A1, B1, etc. The respective experimental densities for solutions with the same composition but without $\mathrm{WB}$, at $25^{\circ} \mathrm{C}$, were (density in $\mathrm{g} \mathrm{mL}^{-1}$; \% difference between calculated and experimental values) $1.06153(-0.1 \%) ; 1.06314(+2.2 \%), 1.07669$ $(+3.1 \%), \quad 1.12865(+3.8 \%), 1.12083(+0.6 \%)$, and 1.15273 $(+2.4 \%) \mathrm{g} \mathrm{mL}{ }^{-1}$. The agreement between the theoretically calculated and experimental densities is therefore excellent.

\section{Results and discussion}

Note: we discuss the calculation of all the parameters required to treat the solvatochromic data in the Calculations section of the ESI. $\dagger$

\subsection{Dependence of $E_{\mathrm{T}}(\mathrm{WB})$ and SB on binary mixture composition}

Fig. 2 shows the dependence of $E_{\mathrm{T}}(\mathrm{WB})$ on $\chi_{\mathrm{W}}$ for $\mathrm{C}_{4} \mathrm{MeImAc}$ and $\mathrm{C}_{3} \mathrm{OMeImAc}$ at $15,25,40$, and $60{ }^{\circ} \mathrm{C}$. In this figure, we exemplify the ideal solvation behavior by straight lines that connect the data for pure IL and W. Fig. 3 and 4 show the (nonlinear) dependence of $E_{\mathrm{T}}(\mathrm{WB})$ and $\mathrm{SB}$ on $\chi_{\mathrm{W}}$ at $25{ }^{\circ} \mathrm{C}$; the maximum deviations from linearity occur at $\chi_{\mathrm{W}}$ values of 0.77
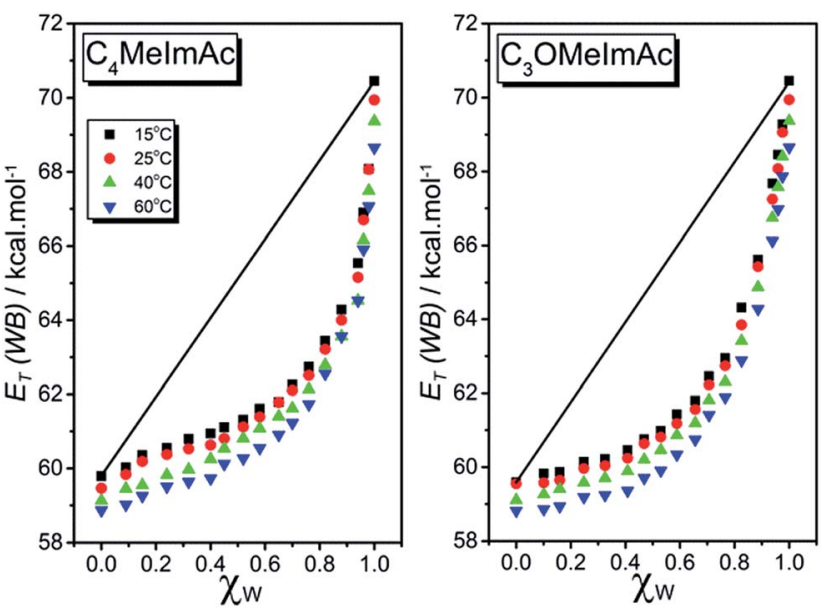

Fig. 2 Dependence of the calculated empirical polarity, $E_{T}(\mathrm{WB})$ on the composition of binary solvent mixtures at $15,25,40$, and $60{ }^{\circ} \mathrm{C}$ for $\mathrm{C}_{4}$ MelmAc-W (left) and $\mathrm{C}_{3} \mathrm{OMelmAc}-\mathrm{W}$ (right). The ideal solvation behavior of WB is depicted by the straight lines drawn between $E_{T}(\mathrm{WB})$ of the pure solvents, shown for the data at $15^{\circ} \mathrm{C}$.

$\left(E_{\mathrm{T}}(\mathrm{WB})\right)$ and $0.71(\mathrm{SB})$ for $\mathrm{C}_{4} \mathrm{MeImAc}$ and $\mathrm{C}_{3} \mathrm{OMeImAc}$. For IL$\mathrm{Cl}$ at the same temperature $\left(25^{\circ} \mathrm{C}\right)$, the maximum deviations from linearity occur at $\chi_{\mathrm{W}}=0.83$ (for $E_{\mathrm{T}}(\mathrm{WB})$ and (SB) and for both $\mathrm{C}_{4} \mathrm{MeImCl}$ and $\mathrm{C}_{3} \mathrm{OMeImCl}$ ).

We calculated the (polynomial) dependence of $E_{\mathrm{T}}(\mathrm{WB})$ on the analytical mole fraction of W; the data is presented in Table ESI$3 . \dagger$ The quality of the fit is indicated by the values of the regression coefficient, $r^{2}$, and $\Sigma Q^{2}$, the sum of the squares of the residuals. The degree of polynomial employed is that which gave the best data fit as indicated by these statistical criteria.

\subsection{Effect of introducing an ether linkage in the IL side chain on the solvatochromic parameters}

The literature shows that the empirical polarity and Lewis basicity of a solvent carrying ether oxygen are higher than those of a hydrocarbon with a related structure except for the absence of oxygen(s). This is shown by comparing $E_{\mathrm{T}}(\mathrm{RB})$ for diethyl ether and $n$-pentane $(34.5,31.0)$, tetrahydrofuran and cyclohexane $(37.4,30.9)$, and 1,2-dimethoxyethane and $n$-heptane $(38.2,31.1) \mathrm{kcal} \mathrm{mol}^{-1}$. Likewise, solvents with ether linkages are more basic than hydrocarbons with related structures as shown by the SB values of diethyl ether and $n$-pentane $(0.562$, $0.07)$ and of tetrahydrofuran and $n$-heptane $(0.591,0.08) .^{3,50}$

Based on the preceding paragraph, the values of $E_{\mathrm{T}}(\mathrm{WB})$ and $\mathrm{SB}$ of pure $\mathrm{C}_{3} \mathrm{OMeImAc}$ and $\mathrm{C}_{3} \mathrm{OMeImAc}-\mathrm{W}$ mixtures are expected to be higher than the corresponding values for pure $\mathrm{C}_{4} \mathrm{MeImAc}$ and $\mathrm{C}_{4} \mathrm{MeImAc}-\mathrm{W}$ mixtures. Surprisingly, the values of both solvatochromic parameters for the pure ILs are practically the same; i.e., they are insensitive to the presence of ether linkages at all temperatures. Fig. 3 and 4 show that $\mathrm{C}_{4} \mathrm{MeImAc}-$ $\mathrm{W}$ is more polar than $\mathrm{C}_{3} \mathrm{OMeImAc}-\mathrm{W}$ at $\chi_{\mathrm{W}}$ values from 0.1 to 0.67 . On the other hand, the former binary mixture is more basic than the latter one over the entire range of $\chi_{\mathrm{W}}$. A similar negligible effect of the side chain structure on $E_{\mathrm{T}}(\mathrm{RB})$ was 

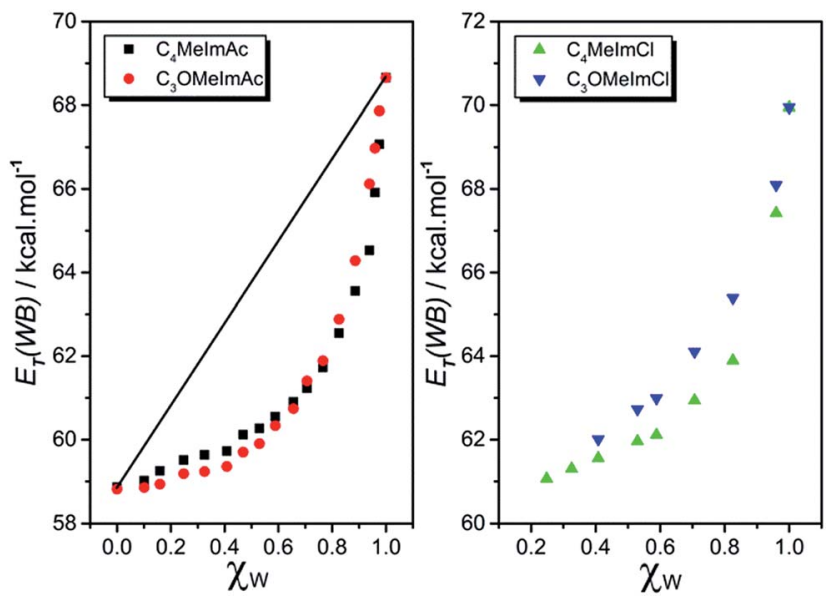

Fig. 3 Dependence of solvent polarity, $E_{\mathrm{T}}(\mathrm{WB})$, on the mole fraction of water in the $\mathrm{IL}-\mathrm{W}$ binary mixtures, $\chi_{\mathrm{W}}$, at $25{ }^{\circ} \mathrm{C}$ for IL-acetates (left) and IL-chlorides (right). Similar to Fig. 2, the ideal solvation behavior of WB is depicted by the straight line drawn between $E_{T}(W B)$ of the pure solvents. As both IL-chlorides are solids, $E_{\mathrm{T}}(\mathrm{WB})$ for pure ILs at $25^{\circ} \mathrm{C}$ cannot be determined. The limited solubility of $\mathrm{IL}$-chlorides in water precluded examination of the entire $\chi_{\mathrm{W}}$ range.

reported for $\mathrm{C}_{4} \mathrm{MeImX}$-acetonitrile and $\mathrm{C}_{3} \mathrm{OMeImX}$-acetonitrile, where $\mathrm{X}=\mathrm{Cl}^{-}, \mathrm{BF}_{4}{ }^{-}$, and $\mathrm{PF}_{6}{ }^{-}{ }^{.1}$

Regarding the possible reasons for this insensitivity, we consider below the basicity of the anion and interactions of the ether oxygen with the hydrogens of the imidazolium cation:

(i) A consequence of the fact that the pyridinium nitrogens of zwitterionic solvatochromic probes, e.g., $\mathrm{RB}$ and $\mathrm{WB}$, are sterically hindered is that their solvatochromic response is governed by hydrogen bonding to the phenolate oxygen, as deduced from NMR data ${ }^{52}$ and theoretical calculations on the solvation of $\mathrm{RB}^{53}$ The species that participate in this bonding include water (most certainly hydrogen bonded to the IL-anion) and the relatively acidic hydrogens of the imidazolium heterocycle, in particular C2-H. ${ }^{54-57}$ Fig. ESI-1† showing the solvation of WB is consistent with this conclusion: the RDF curves for the interactions of the probe phenolate oxygen with water and with $\mathrm{C} 2-\boldsymbol{H}$ of the IL cation are sharp, and their first maxima are located at distances that allow for efficient hydrogen-bonding (parts $\mathrm{C}$ and D; Fig. ESI- $2 \dagger)$. This contrasts with corresponding RDF plots for the probe quaternary nitrogen (parts A and B; Fig. ESI-2 $\dagger$ ), which are much less structured with maxima located at distances that do not allow for efficient interactions (see below for a detailed discussion on the results of MD calculations).

(ii) We assess the effect of the anion by decreasing its hydrogen bonding ability with water. The chloride ions of $\mathrm{C}_{4}$ $\mathrm{MeImCl}$ and $\mathrm{C}_{3} \mathrm{OMeImCl}$ are less basic than the acetate ion. As a first approximation, the order of $E_{\mathrm{T}}(\mathrm{WB})$ and $\mathrm{SB}$ should be $\mathrm{C}_{3} \mathrm{OMeImCl}-\mathrm{W}>\mathrm{C}_{4} \mathrm{MeImCl}-\mathrm{W}$ because of the attenuated effect of the anion. Fig. 3 shows that this is the case for $E_{\mathrm{T}}(\mathrm{WB})$ in the $\chi_{\mathrm{W}}$ range investigated. We were unable to investigate the entire $\chi_{\mathrm{W}}$ range due to the insolubility of these ILs at low $\chi_{\mathrm{W}}$. Therefore, the order of polarity in the water-poor IL-Cl-W mixtures cannot be assessed. Fig. 4 shows that $\mathrm{C}_{4} \mathrm{MeImCl}-\mathrm{W}$ mixtures are more basic than $\mathrm{C}_{3} \mathrm{OMeImCl}-\mathrm{W}$. Therefore, it is unlikely that the solvatochromic response of the probes to the structure of the IL side chain is dominated by the nature of these particular anions; we therefore focused on the cation.

(iii) An obvious possibility is the formation of intramolecular hydrogen bonds in the $\mathrm{C}_{3} \mathrm{OMeIm}^{+}$cation between the ether oxygen and the acidic hydrogens of the imidazolium ring, in particular with (more acidic) C2-H. This bonding, if it occurs, decreases the Lewis basicity of the ether oxygen and the Lewis acidity of the imidazolium ring hydrogens with concomitant attenuation of the difference between solvation by the two ILs. Theoretical chemistry results (DFT calculations and MD simulations) indicated the formation of such intramolecular hydrogen bonds, in particular with $\mathrm{C} 2-\boldsymbol{H}$ in 1-(2-methoxyethyl)3-methylimidazoliumX $\left(\mathrm{X}=\mathrm{Br}^{-}, \mathrm{Cl}^{-}, \mathrm{I}^{-}\right)^{58}$ and the structurally related 1-(2-hydroxyethyl)-3-methyl imidazoliumX $\left(\mathrm{Br}^{-}, \mathrm{Cl}^{-}\right.$, $\left.\mathrm{NO}_{3}{ }^{-}, \mathrm{BF}_{4}{ }^{-}\right) .{ }^{59}$

We carried out two types of theoretical calculations: computations for $\mathrm{C}_{3} \mathrm{OMeIm}^{+}$(gas phase; Fig. 5) to determine the dependence of the electronic energy of conformers on their structures and MD simulations on the solvation of WB in IL-W mixtures (Fig. 6); see Fig. 1 for the IL atom numbering.

Fig. 5 shows the variation of the electronic energy of $\mathrm{C}_{3} \mathrm{OMeIm}^{+}$as a function of the $\mathrm{C} 2-\mathrm{N} 1-\mathrm{C} 7-\mathrm{C} 8$ dihedral angle, which is calculated for the ion in the gas phase (black points) and for the ion solvated in a water continuum (red points). Solvation by water lowers the electronic energy and changes the dihedral angles of the conformers to correspond to energy minima and maxima to some extent. As the two curves are qualitatively similar, we dwell on the curve in the gas phase. The two energy minima (left to right) correspond to A and C in Fig. 6 and refer to the conformations with dihedral angles of $60^{\circ}$ and $260^{\circ}$, respectively. In both conformations, there is a possibility of intramolecular hydrogen bonding between (-O-) and $\mathrm{C} 2-\boldsymbol{H}$ (distance $\mathrm{O} \cdots \boldsymbol{H}-\mathrm{C} 2=0.239 \mathrm{~nm}$ ) or with $\mathrm{C} 5-\boldsymbol{H}$ (distance $\mathrm{O} \cdots \boldsymbol{H}-$ $\mathrm{C} 5=0.243 \mathrm{~nm})$. As C2-H is more acidic than $\mathrm{C} 5-\boldsymbol{H},{ }^{54}$ the former hydrogen-bond is associated with the smallest electronic energy in the curve. In Fig. 5, the two energy maxima (left to right)

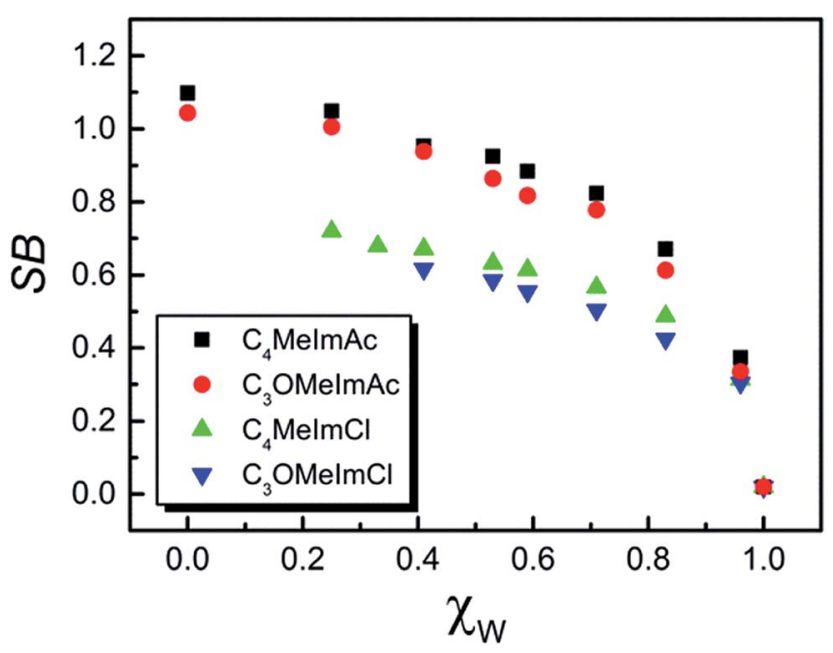

Fig. 4 Dependence of solvent Lewis basicity (SB) on the mole fraction of water, $\chi_{\mathrm{W}}$, at $25^{\circ} \mathrm{C}$ in the IL-W binary mixtures. 


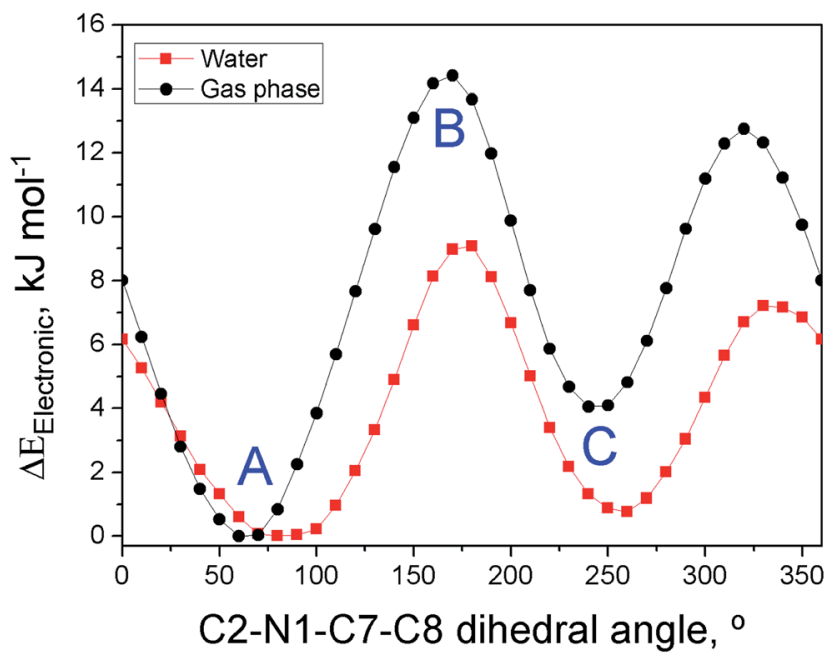

Fig. 5 Dependence of the electronic energy of $\mathrm{C}_{3} \mathrm{OMelm}{ }^{+}$on the C2-N1-C7-C8 dihedral angle calculated for the IL-cation in the gas phase (black) and solvated in a water continuum (red). The conformations of the points marked as (A), (B), and (C) are similar to those depicted in Fig. 6.

correspond to conformations with dihedral angles of $170^{\circ}$ and $320^{\circ}$, respectively; the geometry of the latter is similar to that of (B) in Fig. 6. Therefore, the more stable conformations of the ILcation are those where the ether oxygen is hydrogen-bonded to the relatively acidic hydrogens of the imidazolium ring, which is in agreement with the literature..$^{58}$ This bonding attenuates the Lewis acidity of the imidazolium ring hydrogens and the Lewis basicity of the ether oxygen and leads to the above-mentioned insensitivity of probe solvation to the nature of the IL side chain.

A short comment on MD simulations is in order. These provide the radial distribution function, $g(r)$, that describes the probability of finding an atom at a distance $(r)$ from another one, which is chosen as a reference point. For the present case, we extract information about the solvation of WB from the first $g(r)$ peak (first probe solvation layer); the distances between pairs of atoms, where short distances indicate strong interactions; and the number of interacting species, calculated from the (normalized) areas under the $g(r)$ curve. Note that the MD data calculated were based on the solvation of WB by pure solvents; i.e., there is no provision for the presence of the IL-W complex solvent. This limitation, however, is acceptable because we compare pairs of ILs (with or without oxygen; same anion) to draw conclusions about the effects of the IL side chain on solvation.

The Gromacs program allows calculation of the RDF curves for the intra- and intermolecular interactions between any two atoms, as shown in Fig. ESI-4. $\dagger$ In the latter, the black curve refers to both types of interactions, whereas the red and blue curves represent inter- and intramolecular interactions, respectively. The ratio of integration of the areas of both peaks (after normalization) gives the fraction of molecules with the conformations that produce these peaks. We extended the same treatment to the pair $\mathbf{C} 5-\boldsymbol{H}$ and (-O-); all the results are listed in Table 1.

The following is relevant from the results of Table 1:

(iv) Independently of the value of $\chi_{\mathrm{W}}, 35 \pm 5 \%$ and $20 \pm 2 \%$ of the cations of $\mathrm{C}_{3} \mathrm{OMeImAc}$ have intermolecular hydrogen bonding between (-O-) and $\mathrm{C} 2-\boldsymbol{H}$ and $\mathrm{C} 5-\boldsymbol{H}$, respectively. This agrees with the energy minima in Fig. 5 and with the fact that $\mathrm{C} 2-\boldsymbol{H}$ is more acidic than $\mathbf{C} 5-\boldsymbol{H}$.

(v) For all RDF curves, the maxima of the second peaks lie at ca. $0.43 \mathrm{~nm}$, which is clearly well above the range for efficient hydrogen-bonding. ${ }^{60}$ The reported $\mathrm{O} \cdots \boldsymbol{H}$-C2 distances are not far from that of conformation (B) in Fig. $6(0.468 \mathrm{~nm})$.

In summary, the results in Fig. ESI- $4 \uparrow$ and Table 1 show that a considerable fraction of the cations of $\mathrm{C}_{3} \mathrm{OMeImAc}$ is involved in intramolecular hydrogen bonding between $(-\mathrm{O}-)$ and the acidic hydrogens of the heterocyclic ring. In contrast, a small fraction is involved in efficient intermolecular hydrogen bonding, which is indicated by the shoulder (at $c a .0 .25 \mathrm{~nm}$ ) of the red curve in Fig. ESI-4. $\dagger$ We corroborate these conclusions with two pieces of evidence: the density of the ILs and the ${ }^{1} \mathrm{H}$ NMR data of their solutions in $\mathrm{CDCl}_{3}$.

The (experimental) density of pure $\mathrm{C}_{3} \mathrm{OMeImAc}$ is larger than that of $\mathrm{C}_{4} \mathrm{MeImAc}\left(1.13048\right.$ and $1.05780 \mathrm{~g} \mathrm{~mL}^{-1}$, respectively at $25{ }^{\circ} \mathrm{C}$ ), which is in agreement with published data on other ILs with ether side chains. ${ }^{56}$ These densities correspond to molar volumes of 177.12 and $187.43 \mathrm{~cm}^{3} \mathrm{~mol}^{-1}$, indicating that the preferential conformations of pure $\mathrm{C}_{3} \mathrm{OMeImAc}$ are more compact (i.e., cyclic) than the corresponding ones of (acyclic) $\mathrm{C}_{4}$ MeImAc. Admittedly, the IL molar volumes should be different because of the volume difference between (-O-) and a methylene group, but the ratio of molar volumes of

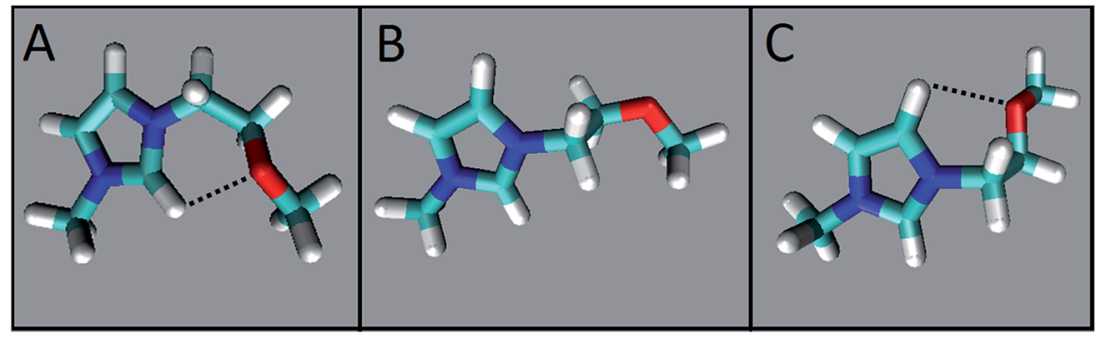

Fig. 6 MD simulation-based snapshots of some limiting conformations of the cation of $C_{3} O$ MelmAc in WB in IL-W at $\chi_{W}=0.67$. The colors used to denote the atoms are red, cyan, white, and navy blue for oxygen, carbon, hydrogen, and nitrogen, respectively. The distances between the atoms are (in $\mathrm{nm}$ ) $\mathrm{O} \cdots H-\mathrm{C} 2=0.239$ (A); $\mathrm{O} \cdots H-\mathrm{C} 2=0.468 \mathrm{~nm}$ (B; open structure); $\mathrm{O} \cdots H-\mathrm{C} 5-=0.243$ (C). 
Table 1 Results from the RDF for the interactions between $\mathrm{C} 2-\mathrm{H}$ or $\mathrm{C} 5-\mathrm{H}$ and (-O-) of the cation of $\mathrm{C}_{3} \mathrm{OMelmAc}$, at different mol fractions of water, $\chi_{\mathrm{w}}$

RDF between $\mathrm{C} 2-\boldsymbol{H}$ and $(-\mathrm{O}-)$

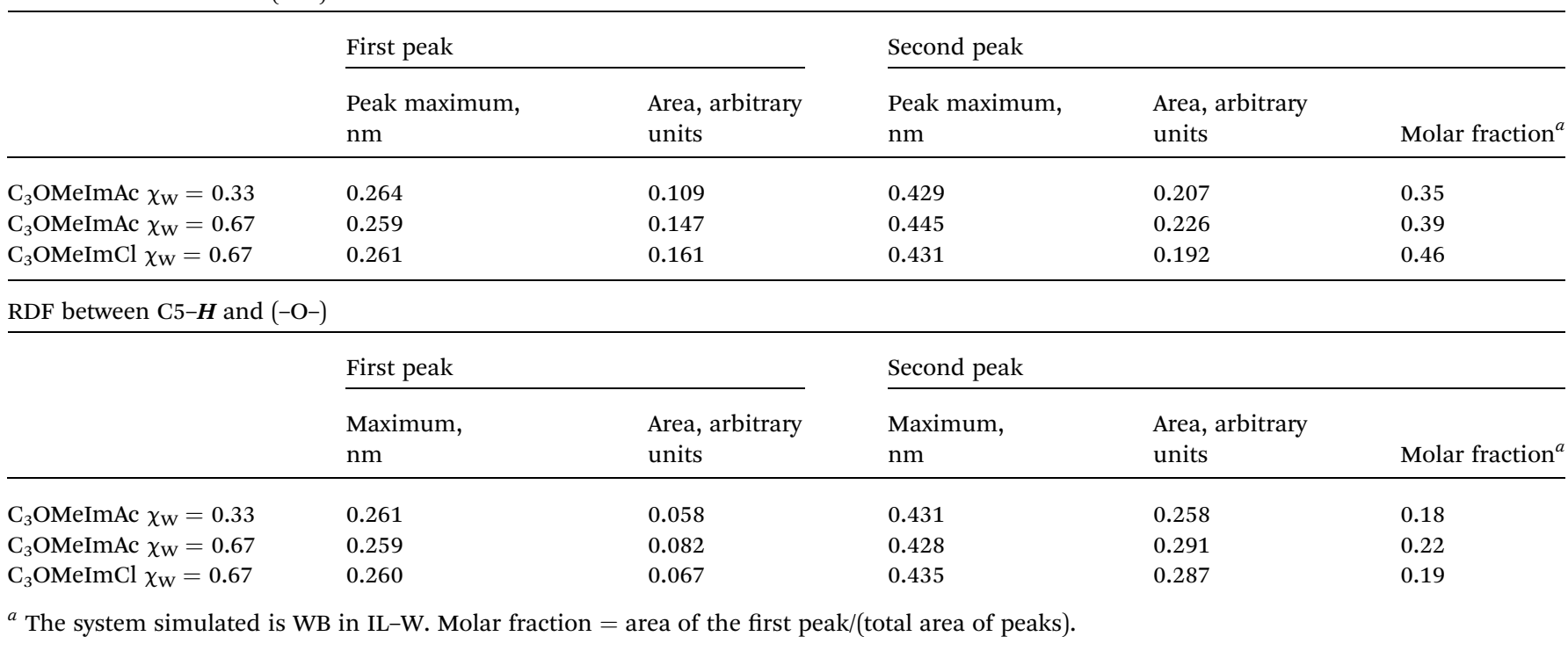

$\mathrm{C}_{3} \mathrm{OMeImAc} / \mathrm{C}_{4} \mathrm{MeImAc}$ is larger (0.945) than those of compounds where intramolecular hydrogen bonding does not occur, e.g., diethyl ether/n-pentane (0.903), tetrahydrofuran/ cyclopentane (0.869), and tetrahydropyran/cyclohexane (0.906).

Further evidence for the formation of intramolecular hydrogen bonding can be deduced from ${ }^{1} \mathrm{H}$ NMR chemical shifts and line widths of the hydrogens of the heterocyclic ring and side chain. We depict the data for solutions of ILs in $\mathrm{CDCl}_{3}$ in Table 2.

Regarding these NMR data, the following is relevant:

(vi) The orders of $\delta_{\mathbf{C 2}-\boldsymbol{H}}$ are $\mathrm{C}_{4} \mathrm{MeImCl}>\mathrm{C}_{3} \mathrm{OMeImCl}$ and $\mathrm{C}_{4} \mathrm{MeImAc}>\mathrm{C}_{3} \mathrm{OMeImAc}$. Assuming equal diamagnetic shielding/deshielding of this hydrogen in each pair of ILs, these orders of $\delta$ may be attributed to the attenuated positive charge on $\mathbf{C} 2-\boldsymbol{H}$ due to hydrogen-bonding with electron-rich species, e.g., the acetate ion and the ether oxygen. ${ }^{62}$ The order of the chemical shifts of $\mathbf{C} 7-\boldsymbol{H}$ and $\mathrm{C} 8-\boldsymbol{H}$ is the opposite and merely reflects the electron-withdrawing inductive effect of the oxygen atom (relative to $-\mathrm{CH}_{2}-$ ).

(vii) The indicated values of $\Delta \nu$ are larger for ILs with an (-O-) side chain. From the relationship between $\Delta \nu$ and the transverse relaxation time $T_{2}\left(\Delta \nu=1 / \pi T_{2}\right), \mathrm{C} 2-\boldsymbol{H}$ of $\mathrm{C}_{3} \mathrm{OMeImCl}$ and $\mathrm{C}_{3} \mathrm{OMeImAc}$ are less mobile (relax faster) than the corresponding hydrogens of $\mathrm{C}_{4} \mathrm{MeImCl}$ and $\mathrm{C}_{4} \mathrm{MeImAc}$, which is in agreement with their participation in intramolecular hydrogenbonding with (-O-). The same argument applies to the values of $\Delta \nu_{\mathbf{C} 7 \boldsymbol{H}}$, which are larger for ILs with an (-O-) side chain, indicating the participation of the attached $\left(-\mathrm{O}^{-}\right)$in hydrogen bonding. We were unable to analyze $\Delta \nu$ for C8- $\boldsymbol{H}$ comparatively because of the different multiplicities of the ILs (triplet for $\mathrm{C}_{3}$ OMeImX and quintet for $\mathrm{C}_{4} \mathrm{MeImX}$ ).

(viii) The dihedral angles calculated from ${ }^{3} J_{\mathbf{C} 7 \mathbf{H}}$ show that the cations of ILs without (-O-), have the side chain, on average, fully extended. Conversely, IL cations with (-O-) have folded side chains with oxygen approaching $\mathrm{C} 2-\boldsymbol{H}$ and $\mathbf{C}-\boldsymbol{H}$ of the imidazolium ring.

\subsection{Analysis of the solvatochromic data in IL-W mixtures}

The observed non-ideal behavior shown in Fig. 2 and 4 may originate from so-called "dielectric enrichment", i.e., enrichment of the probe solvation layer in the solvent of higher

Table $2{ }^{1} \mathrm{H}$ NMR data for solutions of the studied ILs in $\mathrm{CDCl}_{3}$ at $500 \mathrm{MHz}$ and $25^{\circ} \mathrm{C}$

\begin{tabular}{|c|c|c|c|c|c|}
\hline$\delta_{\mathbf{C} 2 \mathbf{H}}$ & $(\mathrm{ppm})$ & 10.53 & 10.40 & 11.25 & 10.89 \\
\hline$\Delta \nu_{\mathrm{C} 2 \boldsymbol{H}}{ }^{a}$ & $(\mathrm{~Hz})$ & 3.8 & 4.4 & 3.9 & 5.8 \\
\hline$\Delta \nu_{\mathrm{C} 7 H}{ }^{a}$ & $(\mathrm{~Hz})$ & 2.4 & 3.0 & 1.6 & 2.8 \\
\hline$\delta_{\mathbf{C 8} H}$ & $(\mathrm{ppm})$ & 1.91 & 3.78 & 1.87 & 3.74 \\
\hline${ }^{3} J_{\mathbf{C} 7 H}$ & $(\mathrm{~Hz})$ & 7.52 & 4.77 & 7.33 & 4.76 \\
\hline
\end{tabular}

${ }^{a} \Delta \nu=$ peak width at half-height. ${ }^{b}$ Calculated using Bothner-By equation: ${ }^{3} J_{\mathrm{HH}}=7-\cos \theta+5 \cos 2 \theta$, where $\theta$ is the dihedral angle between the hydrogens. ${ }^{61}$ 
relative permittivity, $\varepsilon .^{63}$ The value of $\varepsilon$ is $78.5\left(25^{\circ} \mathrm{C}\right)$, whereas it is between 7 and $17.2\left(25^{\circ} \mathrm{C}\right)$ for, respectively, $\mathrm{W}$ and ILs with different cations (including $\left.\mathrm{C}_{4} \mathrm{MeIm}{ }^{+}\right)$and anions $\left(\mathrm{BF}_{4}{ }^{-}, \mathrm{PF}_{6}{ }^{-}\right.$, $\mathrm{Cl}^{-}$, and methyl- to $n$-octyl sulfate). ${ }^{64-66}$ If this solvation mechanism were operative, then the $E_{\mathrm{T}}(\mathrm{WB})$ versus $\chi_{\mathrm{W}}$ plots would have shown positive deviation; i.e., they would have been above the straight line connecting the $E_{\mathrm{T}}(\mathrm{WB})$ values of IL and W; this is not the case. Therefore, we seek another solvation mechanism to explain the non-ideal behavior.

Previously, we introduced a model for describing the solvation of a probe in a binary mixture of two solvents, e.g., IL and W. According to this model, the solvatochromic data are analyzed in terms of the effective (not analytical) concentrations of $\mathrm{IL}, \mathrm{W}$, and a "complex" solvent $(\mathrm{IL}-\mathrm{W})$. As detailed in the ESI, $\dagger$ the latter is formed by the interaction of the two solvents, e.g., via hydrogen bonding, dipolar, and hydrophobic interactions. ${ }^{30,35,38,54-57}$ Based on this treatment, three equilibrium constants (or "fractionation factors", $\varphi$ ) are calculated for the solvent exchange equilibria in the solvation layer of WB. They describe the composition of the probe solvation layer (in W, IL, and $\mathrm{IL}-\mathrm{W}$ ) relative to that of the bulk solvent. We deduce information regarding preferential solvation from the value of $\varphi$. For example, $\varphi_{\mathrm{W} / \mathrm{IL}}>1$ indicates preferential solvation by water. In other words, water displaces the IL from the probe solvation layer; i.e., the latter is richer in $\mathrm{W}$ than the bulk solvent. The converse is true for $\varphi_{\mathrm{W} / \mathrm{IL}}<1$; i.e., the probe is preferentially solvated by IL. Finally, a solvent fractionation factor of unity indicates ideal solvation; i.e., the solvation layer and bulk solvent have the same composition. The same line of reasoning applies to $\varphi_{\mathrm{IL}-\mathrm{W} / \mathrm{IL}}$ (complex solvent displaces IL in the solvation layer) and $\varphi_{\mathrm{IL}-\mathrm{W} / \mathrm{W}}$ (complex solvent displaces $\mathrm{W}$ ). These solvent-exchange equilibria are given by eqn ESI-(5) to ESI-(7). $\dagger$ We carried out these calculations for $E_{\mathrm{T}}(\mathrm{WB})$ in ILacetate- $\mathrm{W}$ because the model fit to the data is reliable due to the large number of binary mixtures examined (18 at each temperature). Table 3 shows the results of these calculations.

Regarding the data in Table 3, the following is relevant:

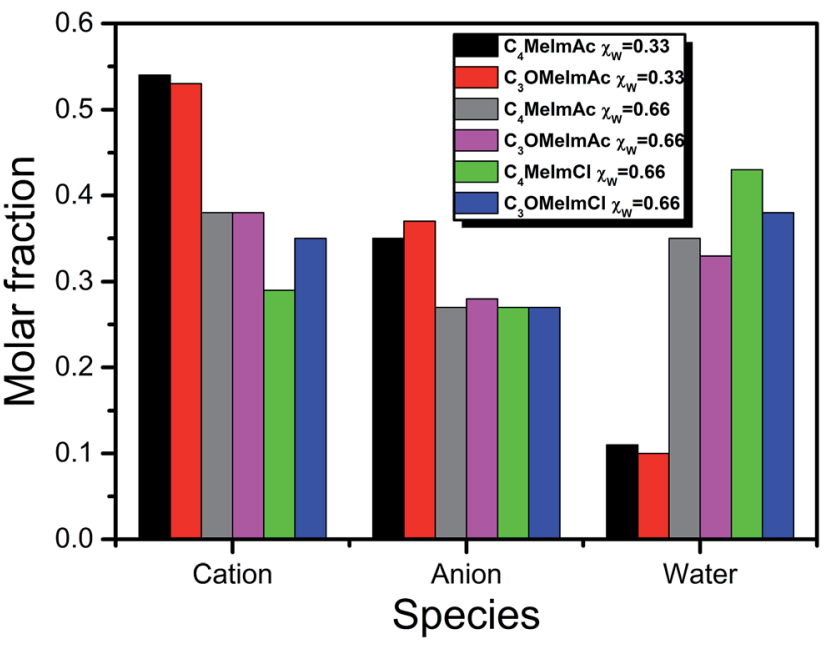

Fig. 7 Composition of the first solvation layer of WB in $\mathrm{IL}-\mathrm{X}(\mathrm{X}=$ acetate and chloride) at different water mole fractions, $\chi_{W}$.

(ix) The quality of fit of the above-discussed solvation model to our data is shown by values of $\left(r^{2}\right)$ and $\Sigma Q^{2}$ and by the excellent agreement between experimental and calculated $E_{\mathrm{T}}(\mathrm{WB})$ in pure solvents at different temperatures.

(x) The second column of Table 3 shows that the values of $(m)$ are close to unity. That is, a small number of solvent molecules perturbs the intramolecular charge transfer between the phenolate oxygen and the quaternary nitrogen of $\mathrm{WB}$, leading to the observed nonlinear dependence of $E_{\mathrm{T}}(\mathrm{WB})$ on $\chi_{\mathrm{W}}$; see Fig. 2.

(xi) The values of all $\varphi_{(\mathrm{W} / \mathrm{IL})}$ are much smaller than unity; i.e., the IL is a better solvent for WB than W, probably because of solvation of the probe (phenolate oxygen) by the relatively acidic hydrogens of the imidazolium ring, which is in agreement with Fig. ESI-2.†

(xii) At any temperature, all values of IL-W/IL and IL-W/W are much larger than unity; i.e., the complex solvent is more efficient than its precursors, which is in agreement with our previous data on solvation of different probes (WB and

Table 3 Data analysis of solvation of WB in mixtures of $\mathrm{IL}-\mathrm{W}$ in the temperature range 15 to $60^{\circ} \mathrm{C}^{a, b, c}$

\begin{tabular}{|c|c|c|c|c|c|c|c|c|c|}
\hline$T,{ }^{\circ} \mathrm{C}$ & $m$ & $\varphi_{(\mathrm{W} / \mathrm{IL})}$ & $\varphi_{(\mathrm{IL}-\mathrm{W} / \mathrm{IL})}$ & $\varphi_{(\mathrm{IL}-\mathrm{W} / \mathrm{W})}$ & $E_{\mathrm{T}}(\mathrm{WB})_{\mathrm{IL}}$ & $E_{\mathrm{T}}(\mathrm{WB})_{\mathrm{W}}$ & $E_{\mathrm{T}}(\mathrm{WB})_{\mathrm{IL}-\mathrm{W}}$ & $r^{2^{\prime}}$ & $\chi^{2}$ \\
\hline \multicolumn{10}{|c|}{ WB in $\mathrm{C}_{4} \mathrm{MeImAc}$-water } \\
\hline $15{ }^{\circ} \mathrm{C}$ & 1.34 & 0.056 & 13.327 & 237.982 & $59.8(+0.3)$ & $70.45(+0.01)$ & 62.9 & 0.99727 & 0.01932 \\
\hline $40{ }^{\circ} \mathrm{C}$ & 1.09 & 0.072 & 6.824 & 94.778 & $59.18(-0.02)$ & $69.37(-0.01)$ & 63.0 & 0.99872 & 0.00853 \\
\hline $60{ }^{\circ} \mathrm{C}$ & 1.00 & 0.115 & 4.111 & 35.748 & $58.6(+0.1)$ & $68.66(-0.04)$ & 62.1 & 0.99758 & 0.01616 \\
\hline $25^{\circ} \mathrm{C}$ & 1.20 & 0.105 & 1.256 & 11.994 & $59.54(+0.003)$ & $69.92(+0.02)$ & 61.5 & 0.99899 & 0.01256 \\
\hline $40^{\circ} \mathrm{C}$ & 1.12 & 0.096 & 0.864 & 9.007 & $59.18(-0.08)$ & $69.36(+0.01)$ & 62.2 & 0.99936 & 0.00759 \\
\hline $60^{\circ} \mathrm{C}$ & 1.08 & 0.116 & 0.739 & 6.387 & $58.76(+0.05)$ & $68.67(-0.02)$ & 60.7 & 0.99927 & 0.00825 \\
\hline
\end{tabular}

${ }^{a}$ Analysis according to eqn ESI-(5) to ESI-(7). The symbols $(m), \varphi_{(\mathrm{W} / \mathrm{IL})}, \varphi_{(\mathrm{IL}-\mathrm{W} / \mathrm{IL})}$, and $\varphi_{(\mathrm{IL}-\mathrm{W} / \mathrm{W})}$ refer to the number of solvent molecules that perturb the intramolecular charge transfer within the probe, and the equilibrium constants of solvent exchange within the probe solvation layer, where $\mathrm{W} /$ IL, IL-W/IL, and IL-W/W refer to water displacing the IL and the complex solvent displacing the IL and W, respectively. See the Calculations section of the ESI. ${ }^{b}$ For pure solvents, the values within parentheses refer to the difference: (experimental $E_{\mathrm{T}}(\mathrm{WB})-$ calculated $\left.E_{\mathrm{T}}(\mathrm{WB})\right) .{ }^{c}$ The values reported for the mixed solvent IL-S were calculated by regression analysis. 

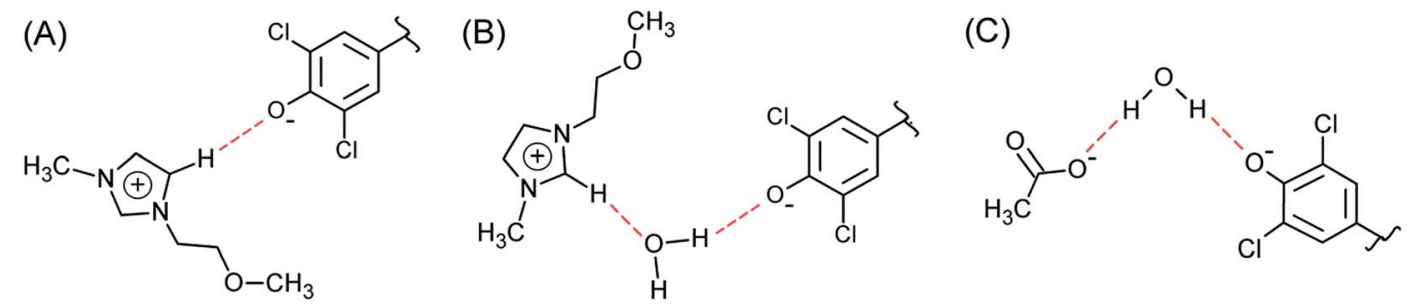

Fig. 8 Schematic of hydrogen bonding between $\left({ }^{-} \mathrm{O}-\mathrm{WB}\right)$ and the binary mixture components. $(\mathrm{A})=\left(\mathrm{C} 5-\mathrm{H} \cdots{ }^{-} \mathrm{O}-\mathrm{WB}\right),(\mathrm{B})=(\mathrm{C} 2-\mathrm{H} \cdots \mathrm{O}(\mathrm{H})$ $\left.\mathrm{H} \cdots{ }^{-} \mathrm{O}-\mathrm{WB}\right)$, and $(\mathrm{C})=\left(\mathrm{CH}_{3} \mathrm{CO}_{2}{ }^{-} \cdots \mathrm{H}-\mathrm{O}-\mathrm{H} \cdots{ }^{-} \mathrm{O}-\mathrm{WB}\right)$; see Fig. 1 for the complete structure of WB.

merocyanines) in aqueous ILs. ${ }^{31,67}$ We discuss this relative efficiency by considering the interactions involved in the solvation of the phenolate oxygen of WB. IL-W is more efficient than IL and $\mathrm{W}$ because it offers more possibilities for hydrogen bonding, e.g., (C5-H $\left.\cdots^{-} \mathrm{O}-\mathrm{WB}\right)$ and $\left(\mathrm{C} 2-\mathrm{H}^{\cdots} \mathrm{O}(\mathrm{H}) \mathrm{H} \cdots^{-} \mathrm{O}-\mathrm{WB}\right)$ simultaneously.

(xiii) Table 3 shows that all fractionation factors are larger for $\mathrm{C}_{4} \mathrm{MeImAc}-\mathrm{W}$ than for $\mathrm{C}_{3} \mathrm{OMeImAc}-\mathrm{W}$; i.e., the former is a more efficient binary solvent. We discuss this result by considering the last column of Table 1 and Fig. 7. Based on the former, we conclude that a sizeable fraction of the $\mathrm{C}_{3} \mathrm{OMeImAc}$ is hardly involved in hydrogen bonding to $\left({ }^{-} \mathrm{O}-\mathrm{WB}\right)$ because some of the atoms concerned $(-\mathrm{O}-, \mathrm{C} 2-\boldsymbol{H}$ and $\mathrm{C} 5-\boldsymbol{H})$ are involved in intramolecular hydrogen bonding. The compositions of the first solvation layers of WB are shown in Fig. 7; the solvent species are given on the mole fraction scale. At each $\chi_{\mathrm{W}}$, there are more IL cations than anions. While the interactions of the IL-cation affect $E_{\mathrm{T}}(\mathrm{WB})$ directly, e.g., via $\left(\mathrm{C} 5-\boldsymbol{H}^{\cdots}{ }^{-} \mathrm{O}-\mathrm{WB}\right)$, and indirectly, e.g., via $\left(\mathrm{C} 2-\boldsymbol{H} \cdots \mathrm{O}(\mathrm{H}) \mathrm{H} \cdots{ }^{-} \mathrm{O}-\mathrm{WB}\right)$, the anion affects solvation indirectly, e.g., via $\left(\mathrm{CH}_{3} \mathrm{CO}_{2}{ }^{-} \cdots \mathrm{H}-\mathrm{O}-\mathrm{H}^{-}{ }^{-} \mathrm{O}-\right.$ $\mathrm{WB}$ ), as shown in Fig. 8. Accordingly, interactions with the ILcation are probably more important than those with the corresponding anion (see also point ii). As discussed above, intramolecular hydrogen bonding deactivates solvation by the cation (with -O-), leading to the observed insensitivity of solvation to the presence of the ether linkage. It is interesting that replacement of (more basic) acetate by chloride results in a reduction in $\chi_{\text {cation }}$ and an increase in $\chi_{\mathrm{W}}$ in the solvation layer, as shown in Fig. 7.

\section{Conclusions}

Depending on the application, the use of mixtures of ILs with molecular solvents rather than pure ILs is advantageous. Rational use of these mixtures requires understanding of the interactions between the components of the medium and between these and the species of interest (solvatochromic probe, biopolymer, and reactant and transition state). We investigated these interactions using solvatochromic probes, an appropriate solvation model, and theoretical calculations.

In order to delineate the effects of the IL cation side chain on solvation (due to replacement of $-\mathrm{CH}_{2}-$ by $-\mathrm{O}-$ ), we studied the solvatochromism of WB in mixtures of water with $\mathrm{C}_{4} \mathrm{MeImX}$ and $\mathrm{C}_{3} \mathrm{OMeImX}(\mathrm{X}=$ acetate and chloride $)$ at different compositions and temperatures. All values of $E_{\mathrm{T}}(\mathrm{WB})$ and $\mathrm{SB}$ showed non- linear dependence on $\chi_{\mathrm{W}}$, with negative deviation from the ideal behavior. We attributed this to preferential solvation of WB by one of the medium components. Because the ether oxygen is more polar and basic than the methylene group, we expected that the $E_{\mathrm{T}}(\mathrm{WB})$ and $\mathrm{SB}$ of pure $\mathrm{C}_{3} \mathrm{OMeImAc}$ and $\mathrm{C}_{3}$ OMeImAc-W should be larger than the corresponding values for pure $\mathrm{C}_{4} \mathrm{MeImAc}$ and $\mathrm{C}_{4} \mathrm{MeImAc}-\mathrm{W}$. This was not the case for $E_{\mathrm{T}}(\mathrm{WB})$ in the $\chi_{\mathrm{W}}$ range $0.1-0.67$ for IL-acetate and for SB over the entire range of $\chi_{\mathrm{W}}$. We attributed these unexpected results to attenuation of the effect of $\left(-\mathrm{O}^{-}\right)$and the hydrogens of the imidazolium ring on solvation resulting from the formation of intramolecular hydrogen bonding. We corroborated this explanation with: quantum chemical calculations that indicated that conformations of $\mathrm{C}_{3} \mathrm{OMeImAc}$ with intramolecular hydrogen-bonding are low energy (Fig. 5 and 6); densities of the pure ILs; and ${ }^{1} \mathrm{H}$ NMR chemical shifts and line widths that indicated the relative immobility of $\mathrm{C} 2-\boldsymbol{H}, \mathrm{C} 5-\boldsymbol{H}$, and $\mathrm{C} 7-\boldsymbol{H}$ due to this hydrogen bonding (Fig. 1 and Table 2). Regarding the solvatochromic data, we assessed the effect of the IL-anion by decreasing its basicity (chloride instead of acetate). Fig. 4 shows that pure $\mathrm{C}_{4} \mathrm{MeImCl}$ and its aqueous solutions are more basic than pure $\mathrm{C}_{3} \mathrm{OMeImCl}$, and $\mathrm{C}_{3} \mathrm{OMeImCl}-\mathrm{W}$. Therefore, it is unlikely that the solvatochromic responses of the probes to the structure of the IL side chain are dominated by the nature of these particular anions. A solvation model based on the formation of the complex solvent IL-W fitted the data nicely. Values of $\varphi$ (equilibrium constants for solvent exchange in the probe solvation layer) indicated that IL-W displaces IL and $\mathrm{W}$ efficiently. IL-W offers more possibilities than IL and $\mathrm{W}$ for hydrogen bonding with the phenolate oxygen of $\mathrm{WB}$, e.g., via $\left(\mathrm{C} 5-\boldsymbol{H}^{-}{ }^{-} \mathrm{O}-\mathrm{WB}\right)$ and indirectly, e.g., via $\left(\mathrm{C} 2-\boldsymbol{H} \cdots \mathrm{O}(\mathrm{H}) \mathrm{H}^{\cdots}{ }^{-} \mathrm{O}-\right.$ $\mathrm{WB}$ ). In summary, $\mathrm{C}_{4} \mathrm{MeImX}-\mathrm{W}$ is more polar (at least within a certain $\chi_{\mathrm{W}}$ range) and more basic than the corresponding $\mathrm{C}_{3} \mathrm{OMeImX}-\mathrm{W}(\mathrm{X}=$ acetate and chloride $)$ because participation of $\left(-\mathrm{O}^{-}\right)$and the imidazolium hydrogens in solvating $\mathrm{WB}$ is suppressed due to the above-mentioned intramolecular hydrogen bonding. Hydrogen NMR, solvatochromic data, and the results of MD simulations confirmed this conclusion.

\section{Acknowledgements}

J. C. de Jesus and O. A. El Seoud thank FAPESP (grants 2016/ 13932-7, 2014/22136-4) for the research fellowship and financial support of this work, respectively; O. A. El Seoud thanks CNPq for a research productivity fellowship (grant 307022/2014- 
5); R. Mustafa thanks CNPq and TWAS for a research fellowship. We thank Dr P. Farahani and Prof. K. Coutinho for helpful comments.

\section{References}

1 C. Chiappe and D. Pieraccini, Ionic liquids: solvent properties and organic reactivity, J. Phys. Org. Chem., 2005, 18, 275-297.

2 G. G. Fortunato, P. M. Mancini, M. V. Bravo and C. G. Adam, New Solvents Designed on the Basis of the MolecularMicroscopic Properties of Binary Mixtures of the Type (Protic Molecular Solvent + 1-Butyl-3-methylimidazoliumBased Ionic Liquid), J. Phys. Chem. B, 2010, 114, 1180411819.

3 C. Reichardt and T. Welton, Solvents and Solvent Effects in Organic Chemistry, Wiley-VCH, New York, 3rd edn, 2003, p. 534.

4 C. G. Adam, M. V. Bravo, P. M. E. Mancini and G. G. Fortunato, Solvatochromic dipolarity micro-sensor behaviour in binary solvent systems of the (water + ionic liquid) type: application of preferential solvation model and linear solvation energy relationships, J. Phys. Org. Chem., 2014, 27, 841-849.

5 Z. Z. Bin, H. Matsumoto and K. Tatsumi, Low-melting, lowviscous, hydrophobic ionic liquids: aliphatic quaternary ammonium salts with perfluoroalkyltrifluoroborates, Chem.-Eur. J., 2005, 11, 752-766.

$6 \mathrm{~K}$. Tsunashima and M. Sugiya, Physical and electrochemical properties of low-viscosity phosphonium ionic liquids as potential electrolytes, Electrochem. Commun., 2007, 9, 23532358.

7 S. V. Dzyuba and R. A. Bartsch, Expanding the polarity range of ionic liquids, Tetrahedron Lett., 2002, 43, 4657-4659.

8 J. D. Holbrey, M. B. Turner, W. M. Reichert and R. D. Rogers, New ionic liquids containing an appended hydroxyl functionality from the atom-efficient, one-pot reaction of 1methylimidazole and acid with propylene oxide, Green Chem., 2003, 5, 731-736.

9 P. Petiot, C. Charnay, J. Martinez, L. Puttergill, F. Galindo, F. Lamaty and E. Colacino, Synthesis of a new hydrophilic poly(ethylene glycol)-ionic liquid and its application in peptide synthesis, Chem. Commun., 2010, 46, 8842-8844.

10 Y. Deng, P. Besse-Hoggan, M. Sancelme, A. M. Delort, P. Husson and M. F. Costa Gomes, Influence of oxygen functionalities on the environmental impact of imidazolium based ionic liquids, J. Hazard. Mater., 2011, 198, 165-174.

11 S. Fang, L. Yang, J. Wang, M. Li, K. Tachibana and K. Kamijima, Ionic liquids based on functionalized guanidinium cations and TFSI anion as potential electrolytes, Electrochim. Acta, 2009, 54, 4269-4273.

12 S. Fang, Z. Zhang, Y. Jin, L. Yang, S. I. Hirano, K. Tachibana and J. Kamijima, New functionalized ionic liquids based on pyrrolidinium and piperidinium cations with two ether groups as electrolytes for lithium battery, J. Power Sources, 2011, 196, 5637-5644.
13 A. J. R. Rennie, N. Sanchez-Ramirez, R. M. Torresi and P. J. Hall, Ether-bond-containing ionic liquids as supercapacitor electrolytes, J. Phys. Chem. Lett., 2013, 4, 2970-2974.

14 M. Díaz, A. Ortiz and I. Ortiz, Progress in the use of ionic liquids as electrolyte membranes in fuel cells, J. Membr. Sci., 2014, 469, 379-396.

15 G. Cui, C. Wang, J. Zheng, Y. Guo, X. Luo and H. Li, Highly efficient $\mathrm{SO}_{2}$ capture by dual functionalized ionic liquids through a combination of chemical and physical absorption, Chem. Commun., 2012, 48, 2633-2635.

16 G. B. Damas, A. B. A. Dias and L. T. Costa, A quantum chemistry study for ionic liquids applied to gas capture and separation, J. Phys. Chem. B, 2014, 118, 9046-9064.

17 H. Zhao, C. L. Jones and J. V. Cowins, Lipase dissolution and stabilization in ether-functionalized ionic liquids, Green Chem., 2009, 11, 1128-1138.

18 H. Zhao, G. A. Baker and J. V. Cowins, Fast enzymatic saccharification of switchgrass after pretreatment with ionic liquids, Biotechnol. Prog., 2010, 26, 127-133.

19 A. Parviainen, A. W. T. King, I. Mutikainen, M. Hummel, C. Selg, L. K. J. Hauru, H. Sixta and I. Kilpeläinen, Predicting cellulose solvating capabilities of acid-base conjugate ionic liquids, ChemSusChem, 2013, 6, 2161-2169.

20 S. Tang, G. A. Baker and H. Zhao, Ether- and alcoholfunctionalized task-specific ionic liquids: attractive properties and applications, Chem. Soc. Rev., 2012, 41, 4030-4066.

21 C. Chiappe and C. S. Pomelli, Point-functionalization of ionic liquids: an overview of synthesis and applications, Eur. J. Org. Chem., 2014, 28, 6120-6139.

22 V. G. Machado, R. I. Stock and C. Reichardt, Pyridinium NPhenolate Betaine Dyes, Chem. Rev., 2014, 114, 10429-10475.

23 S. Tiwari, N. Khupse and A. Kumar, Intramolecular DielsAlder reaction in ionic liquids: effect of ion-specific solvent friction, J. Org. Chem., 2008, 73, 9075-9083.

24 A. Manna and A. Kumar, Invoking Pairwise Interactions in Water-Promoted Diels-Alder Reactions by using Ionic Liquids as Cosolvents, ChemPhysChem, 2014, 15, 3067-3077.

25 A. M. Stepan, A. Michud, S. Hellstén, M. Hummel and H. Sixta, Pulp Fractionation and Fiber Spinning with Ionic Liquids, Ind. Eng. Chem. Res., 2016, 55, 8225-8233.

26 R. Bianchini, G. Cevasco, C. Chiappe, C. S. Pomelli and M. J. Rodríguez Douton, Ionic Liquids Can Significantly Improve Textile Dyeing: An Innovative Application Assuring Economic and Environmental Benefits, ACS Sustainable Chem. Eng., 2015, 3, 2303-2308.

27 A. Stoppa, J. Hunger and R. Buchner, Conductivities of Binary Mixtures of Ionic Liquids with Polar Solvents, J. Chem. Eng. Data, 2009, 54, 472-479.

28 J. N. C. Lopes, M. F. C. Gomes, P. Husson, A. H. P. Agílio, L. P. N. Rebelo, S. Sarraute and M. Tariq, Polarity, Viscosity, and Ionic Conductivity of Liquid Mixtures Containing $\left[\mathrm{C}_{4} \mathrm{C}_{1} \mathrm{Im}\right]\left[\mathrm{Ntf}_{2}\right]$ and a Molecular Component, $J$. Phys. Chem. B, 2011, 115, 6088-6099.

29 V. Govinda, P. Attri, P. Venkatesu and P. Venkateswarlu, Thermophysical properties of dimethylsulfoxide with ionic 
liquids at various temperatures, Fluid Phase Equilib., 2011, 304, 35-43.

30 B. M. Sato, C. G. G. de Oliveira, C. T. Martins and O. A. El Seoud, Thermo-solvatochromism in binary mixtures of water and ionic liquids: on the relative importance of solvophobic interactions, Phys. Chem. Chem. Phys., 2010, 12, 1764-1771.

31 B. M. Sato, C. T. Martins and O. A. El Seoud, Solvation in aqueous binary mixtures: consequences of the hydrophobic character of the ionic liquids and the solvatochromic probes, New J. Chem., 2012, 36, 2353-2360.

32 L. K. J. Hauru, M. Hummel, A. W. T. King, I. Kilpeläinen and H. Sixta, Role of solvent parameters in the regeneration of cellulose from ionic liquid solutions, Biomacromolecules, 2012, 13, 2896-2905.

33 K. A. Le, R. Sescousse and T. Budtova, Influence of water on cellulose-EMIMAc solution properties: a viscometric study, Cellulose, 2012, 19, 45-54.

34 T. A. Bioni, E. P. G. Areas, L. G. Couto, G. Favarin and O. A. El Seoud, Dissolution of cellulose in mixtures of ionic liquid and molecular solvents: relevance of solvent-solvent and cellulose-solvent interactions, Nord. Pulp Pap. Res. J., 2015, 30, 105-111.

35 O. A. El Seoud, Understanding solvation, Pure Appl. Chem., 2009, 81, 697-707.

36 A. V. Ladesov, D. S. Kosyakov, K. G. Bogolitsyn and N. S. Gorbova, Solvatochromic Polarity Parameters for Binary Mixtures of 1-Butyl-3-Methylimidazolium Acetate with Water, Methanol, and Dimethylsulfoxide, Russ. J. Phys. Chem. A, 2015, 89, 1814-1820.

37 W. L. F. Armarego and C. L. L. Chai, Purification of Laboratory Chemicals, Elsevier, New York, 5th edn, 2003.

38 C. T. Martins, B. M. Sato and O. A. El Seoud, First study on the thermo-solvatochromism in aqueous 1-(1-butyl)-3methylimidazolium tetrafluoroborate: a comparison between the solvation by an ionic liquid and by aqueous alcohols, J. Phys. Chem. B, 2008, 112, 8330-8339.

39 S. A. Dharaskar, M. N. Varma, D. Z. Shende, C. K. Yoo and K. L. Wasewar, Synthesis, characterization and application of 1-butyl-3 methylimidazolium chloride as green material for extractive desulfurization of liquid fuel, Sci. World J., 2013, 1-9.

40 Gaussian-09, revision D-01, Gaussian Inc., Wallingford CT, 2009.

41 D. Van Der Spoel, E. Lindahl, B. Hess, G. Groenhof, A. E. Mark and H. J. C. Berendsen, GROMACS: Fast, flexible, and free, J. Comput. Chem., 2005, 26, 1701-1718.

42 H. J. C. Berendsen, J. R. Grigera and T. P. Straatsma, The Missing Term in Effective Pair Potentials, J. Phys. Chem., 1987, 91, 6269-6271.

43 F. Neese, U. Becker, D. Ganiouchine, S. Koßmann, T. Petrenko, C. Riplinger and F. Wennmohs, Orca - an $a b$ initio, DFT and semiempirical SCF-MO package, University of Bonn, Germany, 2011.

44 C. C. I. Bayly, P. Cieplak, W. D. Cornell and P. A. Kollman, A well-behaved electrostatic potential based method using charge restraints for deriving atomic charges: the RESP model, J. Phys., 1993, 97, 10269-10280.

45 M. Kohagen, M. Brehm, Y. Lingscheid, R. Giernoth, J. Sangoro, F. Kremer, S. Naumov, C. Jacob, J. Kärger, R. Valiulins and B. Kirchner, How Hydrogen Bonds Influence the Mobility of Imidazolium-Based Ionic Liquids. A Combined Theoretical and Experimental Study of 1- $n$ Butyl-3-methylimidazolium Bromide, J. Phys. Chem. B, 2011, 115, 15280-15288.

46 E. Vanquelef, S. Simon, G. Marquant, E. Garcia, G. Klimerak and J. C. Delepine, R. E. D. server: a web service for deriving RESP and ESP charges and building force field libraries for new molecules and molecular fragments, Nucleic Acids Res., 2011, W511-W517.

47 A. W. S. Silva and W. F. Vranken, ACPYPE - AnteChamber PYthon Parser interfacE, BMC Res. Notes, 2012, 5, 367.

48 J. Wang, W. Wang, P. A. Kollman and D. A. Case, Automatic atom type and bond type perception in molecular mechanical calculations, J. Mol. Graphics Modell., 2006, 25, 247-260.

49 L. Martínez, R. Andrade, E. G. Birgin and J. M. Martínez, Packmol: A package for building initial configurations for molecular dynamics simulations, J. Comput. Chem., 2009, 30, 2157-2164.

50 J. Catalán, Toward a generalized treatment of the solvent effect based on four empirical scales: dipolarity (SdP, a new scale), polarizability (SP), acidity (SA), and basicity (SB) of the medium, J. Phys. Chem. B, 2009, 113, 5951-5960.

51 R. M. Couto, C. Lourenço, J. C. Lima, P. C. Simões and L. C. Branco, Studies of the influence in acetonitrile polarity using imidazolium ionic liquids as additives, $J$. Chem. Eng. Data, 2013, 58, 1449-1453.

52 J. G. Dawber and R. A. Williams, A Nuclear Magnetic Resonance Study of the Solvatochromism of a Pyridinium Betaine, J. Chem. Soc., Faraday Trans. 1, 1986, 82, 3097-3112.

53 C. Chiappe and C. S. Pomelli, The first solvation shell of Reichardt's dye in ionic liquids: a semiempirical study, Theor. Chem. Acc., 2012, 131, 1195-2001.

54 S. Sowmiah, V. Srinivasadesikan, M. C. Tseng and Y. H. Chu, On the chemical stabilities of ionic liquids, Molecules, 2009, 14, 3780-3813.

55 A. Samanta, Solvation dynamics in ionic liquids: What we have learned from the dynamic fluorescence Stokes shift studies, J. Phys. Chem. Lett., 2010, 1, 1557-1562.

56 Z. J. Chen, T. Xue and J.-M. Lee, What causes the low viscosity of ether-functionalized ionic liquids? Its dependence on the increase of free volume, RSC Adv., 2012, 2, 10564-10574.

57 Z.-D. Ding, Z. Chi, W.-X. Gu, S.-M. Gu and H.-J. Wang, Theoretical and experimental investigation of the interactions between [emim]Ac and water molecules, $J$. Mol. Struct., 2012, 1015, 147-155.

58 Z. Fei, W. H. Ang, D. Zhao, R. Scopelliti, E. E. Zvereva, S. A. Katsyuba and P. J. Dyson, Revisiting Ether-Derivatized Imidazolium-Based Ionic Liquids, J. Phys. Chem. B, 2007, 111, 10095-10108. 
59 M. Fakhraee, B. Zandkarimi, H. Salari and M. R. Gholami, Ionic Liquids: Thermodynamic and Structural Properties using Molecular Dynamics Simulations and $a b$ Initio Calculations, J. Phys. Chem. B, 2014, 118, 14410-14428.

60 E. Arunan, G. R. Desiraju, R. A. Klein, J. Sadlej, S. Scheiner, I. Alkorta, D. C. Clary, R. H. Crabtree, J. J. Dannenberg, P. Hobza, H. G. Kjaergaard, A. C. Legon, B. Mennucci and D. J. Nesbitt, Defining the hydrogen bond: An account (IUPAC Technical Report), Pure Appl. Chem., 2011, 83, 1619-1636.

61 E. D. Becker, High Resolution NMR: Theory and Chemical Applications, Academic Press, San Diego, 2000, p. 119.

62 W. Beichel, N. Trapp, C. Hauf, O. Kohler, G. Eickerling, W. Scherer and I. Krossing, Charge-scaling effect in ionic liquids from the charge-density analysis of $N, N^{\prime}$ dimethylimidazolium methylsulfate, Angew. Chem., Int. Ed., 2014, 53, 3143-3146.

63 P. Suppan and N. Ghoneim, in Solvatochromism, The Royal Society of Chemistry, Cambridge, 1997, pp. 21-67.
64 P. W. Khirade, A. Chaudhari, J. B. Shinde, S. N. Helambe and S. C. Mehrotra, Static dielectric constant and relaxation time measurements on binary mixtures of dimethyl sulfoxide with ethanol, 2-ethoxyethanol, and propan-1-ol at 293, 303, 313, and 323 K, J. Chem. Eng. Data, 1999, 44, 879-881.

65 M. Uematsu and E. U. Frank, Static Dielectric Constant of Water and Steam, J. Phys. Chem. Ref. Data, 1980, 9, 12911306.

66 T. Singh and A. Kumar, Static Dielectric Constant of Room Temperature Ionic Liquids: Internal Pressure and Cohesive Energy Density Approach, J. Phys. Chem. B, 2008, 112, 12968-12972.

67 P. L. Silva, M. S. Trassi, C. T. Martins and O. A. El Seoud, Solvatochromism in binary mixtures: first report on a solvation free energy relationship between solvent exchange equilibrium constants and the properties of the medium, J. Phys. Chem. B, 2009, 113, 9512-9519. 